\title{
Performance of an Elite Strawberry Population Derived from Wild Germplasm of Fragaria chiloensis and $F$. virginiana
}

\author{
Travis L. Stegmeir \\ Department of Horticulture, Michigan State University, East Lansing, MI \\ 48824
}

Chad E. Finn

U.S. Department of Agriculture-Agricultural Research Service, Horticultural Crops Research Laboratory, Northwest Center for Small Fruit Research, Corvallis, OR 97330

\author{
Ryan M. Warner \\ Department of Horticulture, Michigan State University, East Lansing, MI \\ 48824
}

\author{
James F. Hancock ${ }^{1}$ \\ Department of Horticulture, Michigan State University, 342 Plant and Soil \\ Sciences Building, East Lansing, MI 48824
}

Additional index words. Fragaria $\times$ ananassa, strawberry reconstruction, remontancy

\begin{abstract}
Fragaria $\times$ ananassa Duchesne ex Rozier, or the cultivated strawberry, resulted from the hybridization of two wild species, $F$. chiloensis (L.) Miller and $F$. virginiana Miller. In an attempt to recreate the cultivated strawberry, elite clones of $F$. chiloensis and $F$. virginiana were crossed within species and then hybridized to produce 26 reconstructed populations. Of these populations, FVC11 [(Frederick $9 \times$ LH 50-4) $\times$ (Scotts Creek $\times 2$ MAR 1A)] had unusually large fruit size and was selected for further analysis. In the summer of 2008,78 individuals of this population were evaluated for their seasonal flowering patterns, inflorescence number, inflorescence height, crown production, flower number, fruit size, yield, internal color, soluble solids, fruit firmness, and plant vigor. Progeny means were compared with those of the parental means and most traits exhibited transgressive segregation, most notably yield and fruit weight. Significant positive correlations were found between many of the production traits, although there were significant negative correlations between fruit firmness and flower number per inflorescence, fruit firmness and soluble solids, and yield per plant and soluble solids. Overall performance scores were assigned to each genotype by summing their relative performance for each trait in the population. Individuals were identified that combined high values for fruit weight and yield with higher than average values for fruit color, firmness, and soluble solids. Use of this population in breeding programs could help expand the genetic base of the cultivated strawberry with limited linkage drag.
\end{abstract}

The primary cultivated strawberry, Fragaria $\times$ ananassa Duchesne ex Rozier, is believed to have arisen from a chance hybridization between the octoploid species $F$. chiloensis (L.) Miller subsp. chiloensis forma chiloensis and $F$. virginiana Miller subsp. virginiana in Europe $\approx 250$ years ago (Hancock, 1999). This hybridization combined the unique characteristics of both species, including the larger, firmer fruit of $F$. chiloensis with the darker red, more aromatic fruit of $F$. virginiana.

Sjulin and Dale (1987), comparing the pedigrees of 134 North American strawberry

Received for publication 19 Jan. 2010. Accepted for publication 17 May 2010.

${ }^{1}$ To whom reprint requests should be addressed; e-mail hancock@msu.edu. greater success if they reconstituted $F$. $\times$ ananassa by intercrossing elite wild $F$. virginiana and $F$. chiloensis parents. This would increase the genetic base of $F$. ×ananassa and introduce novel genetic diversity into the cultivated gene pool (Hancock et al., 1993).

Potential problems with introgressing wild germplasm into $F$. ×ananassa include the possibility of incorporating unfavorable alleles through linkage drag. It has also been suggested that by incorporating wild germplasm into a breeding program, several generations of improvement will be necessary to restore fruit quality to that of industry standard (Scott and Lawrence, 1975), especially when using the small, soft-fruited $F$. virginiana (Scott, 1959). Previous studies have found that at least three rounds of back-crossing back to $F$. Xananassa were necessary to recover genotypes meeting commercial standards (Bringhurst and Voth, 1978; Scott and Lawrence, 1975).

Wild-collected clones of both species have been evaluated in multiple locations to identify the possible beneficial traits that could be incorporated into the cultivated strawberry and thereby select elite germplasm (Hancock et al., 2001a, 2001b). At least eight wild clones have been introgressed into $F$. ×ananassa since the 1920s (Sjulin and Dale, 1987), bringing in such traits as dayneutrality, red stele and strawberry aphid resistance, drought and salinity tolerance, and winter-hardiness (Barritt and Shanks, 1980; Bringhurst and Voth, 1984; Daubeny, 1990; Galletta et al., 1989). Other promising traits that could be introgressed are a higher photosynthetic rate, lower requirements for fertilizer, heat tolerance, resistance to soil pathogens and vigor from $F$. chiloensis, and resistance to soil pathogens, vigor and resistance to powdery mildew, and scorch from $F$. virginiana (Bringhurst et al., 1977; Cameron and Hartley, 1990; Hancock et al., 2001b, 2002; Scott et al., 1972).

In a previous study (Hancock et al., 2010), elite selections of $F$. virginiana and $F$. chiloensis were intercrossed in 23 combinations and evaluated in the field in Michigan and Oregon. The most impressive family was FVC11 [(Frederick $9 \times$ LH 50-4) $\times($ Scotts Creek $\times 2$ MAR 1A)], which had the best combination of fruit size, color, and yield and was composed of four different subspecies: $F$. virginiana ssp. virginiana from Ontario (Frederick 9, PI 612493), F. virginiana ssp. glauca from Montana (LH 50-4, PI 612495), $F$. chiloensis ssp. chiloensis forma patagonica from Chile (2 MAR 1A, PI 602567), and $F$. chiloensis ssp. pacifica from California (Scotts Creek, PI 612490). Herein, the population derived from this complex hybrid was more extensively studied for various horticultural traits, including plant and fruit characteristics.

\section{Materials and Methods} 1993) and could slow the development of new cultivars in response to these challenges (Luby et al., 1991). Because the original hybridization appears to have been accidental, it has been proposed that breeders could achieve
In the fall of 2006, rooted runners from all 78 genotypes of FVC11 that were previously evaluated were dug and transferred to East 
Lansing, MI, from Corvallis, OR, and Benton Harbor, MI, without virus testing. The genotypes were transplanted into a commercial potting mix in $10 \times 10 \times 15$-cm pots and placed in an unheated greenhouse. In June 2007, two to three replicates (runner plants)

of each genotype were set in the field in Benton Harbor, MI, in a randomized complete block design. Plants were set in rows at $1.2 \mathrm{~m} \times 1.2-\mathrm{m}$ spacing and all runners were trained by cross-cultivation into a $1.2 \times 1.2-\mathrm{m}$ square.

Table 1. $T$-test comparing means of remontant (RM) and non-remontant (NRM) genotypes for the FVC11 population evaluated at Benton Harbor, MI.

\begin{tabular}{lcrr}
\hline Trait & NRM mean & RM mean & t value \\
\hline Inflorescences per mother & 5.86 & 8.09 & 2.63 \\
Inflorescences per daughter & 1.71 & 1.79 & 0.59 \\
Flowers per inflorescence & 5.63 & 5.31 & -1.21 \\
Inflorescence height $(\mathrm{cm})$ & 9.84 & 9.76 & -0.13 \\
Crowns per mother & 4.25 & 5.08 & 1.57 \\
Crowns per daughter & 1.44 & 1.51 & 0.82 \\
Daughters per mother & 9.39 & 6.87 & -3.07 \\
Vigor (1 to 7) & 4.07 & 3.65 & -2.35 \\
Fruit weight (g) & 6.88 & 11.97 & 3.94 \\
Total yield (g) & 21.74 & 22.63 & 0.70 \\
Internal color (\%) & 57.75 & 54.73 & 0.60 \\
Soluble solids (Brix) & 8.58 & 8.58 & 0.04 \\
Firmness $\left(\mathrm{g} \cdot \mathrm{mm}^{-2}\right)$ & 153.51 & 152.5 & -0.28 \\
\hline
\end{tabular}

Genotypes were evaluated for their seasonal flowering patterns in 2007 and 2008 from mid-July to early September. Genotypes were considered remontant if they flowered in the beginning of the season and after 21 July when day length exceeded $13 \mathrm{~h}$. Waiting until this date allowed any flowers that had been initiated under shorter days to finish blooming before the data were collected (Hancock et al., 2002). All other plants were considered to be non-remontant. We have chosen the term remontant rather than the more common classification of day-neutral, because evidence is accumulating that repeat flowering is more strongly regulated by temperature than photoperiod (Bradford et al., 2010).

In early June 2008, data were taken on several reproductive and vegetative traits of each mother plant and three randomly selected daughter plants (when available) per plot. Three random inflorescences were selected per mother and daughter plant and
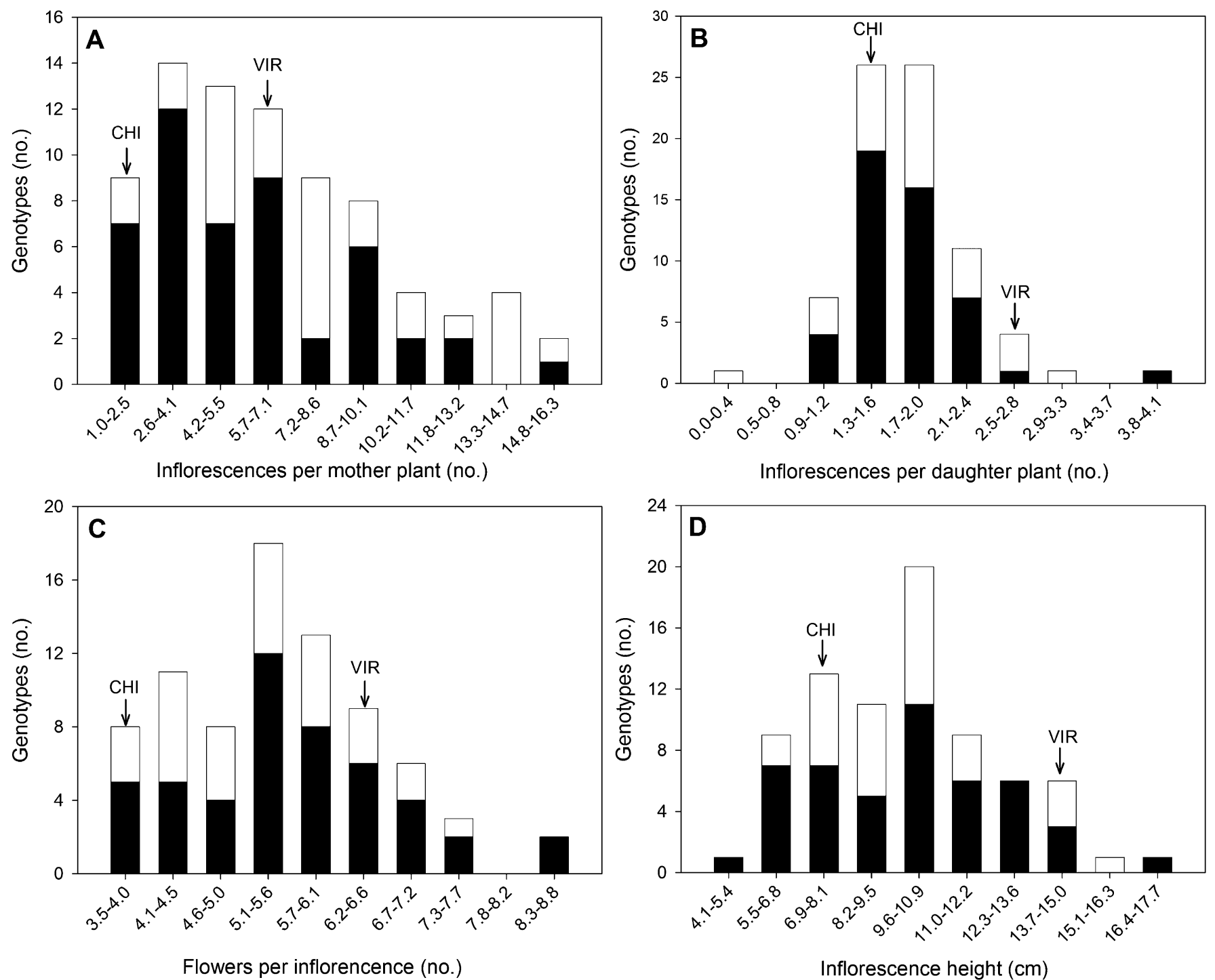

Fig. 1. Number of FVC11 genotypes at Benton Harbor, MI, that had different numbers of inflorescences per mother plant (A), number of inflorescences per daughter plant (B), number of flowers per inflorescence $(\mathbf{C})$, and inflorescent heights $(\mathbf{D})$. Black bars denote progeny that were non-remontant, whereas white bars denote progeny that were remontant in 2008. Arrows show the values of the Fragaria virginiana (VIR) and F. chiloensis (CHI) parents. 
their heights were measured from crown to tip and their flower numbers were counted. The number of crowns was also counted on each mother plant and the three daughter plants as well as the total number of plants within the block for each genotype. Overall plant vigor was estimated on a 1 to 7 (least to most vigorous) scale based on plot fill and individual plant vigor.

During the 2008 fruiting season (9 June to 17 July), the plots were assessed approximately every $5 \mathrm{~d}$ and when at least five ripe fruit appeared, all ripe fruit were harvested. The plots were picked again when another five fruit per block were ripe; however, this time, the ripe and unripe fruit were picked. If a plot had fewer than five fruit, all those available were picked when ripe. Mean fruit weight was calculated for the first five ripe berries in each plot. Mean yield per plant per plot was also determined by dividing the total weight of green and ripe fruit from each genotype by the total number of plants in each plot.
Fruit firmness $\left(\mathrm{g} \cdot \mathrm{mm}^{-2}\right)$ was measured on five ripe fruit per plot (when available) using the compression test of BioWorks' FirmTech 2 (Wamego, KS). Two ripe fruits from each replication were cut in half and percent internal color was estimated based on how deep the color penetrated the flesh. Soluble solids were taken by squeezing one drop of juice onto the handheld refractometer from the two fruits for two separate readings.

Pearson correlation values were calculated for 13 plant, flower, and fruit characteristics using mean genotype values. The analysis was run using SPSS Version 16 (Chicago, IL). Correlation values were considered significant at a 0.05 level. $T$ tests were used to compare the average values of the remontant and nonremontant genotypes using PROC TEST in SAS 9.1.3 (Cary, NC).

The overall performance of each genotype was rated by dividing the mean value for each genotype by the highest value of any genotype for fruit internal color, soluble solids, yield per plant, firmness, inflorescence height, daughter per mother, vigor, and fruit weight to give a value less than or equal to 1 for each trait. The values for each genotype's traits were then added to generate a total performance score. The performance score was generated to identify the most elite genotypes overall for future breeding crosses.

\section{Results}

In 2007, 25 genotypes were remontant with 21 repeat-flowering in more than one replicate (strongly remontant) and another four repeat-flowering in just one replicate (weakly remontant). Twenty-nine genotypes were classified as remontant in 2008 with 21 being strong and eight being weak. Neither of the parents was classified as remontant in 2007, and the $F$. virginiana parent performed as a weak remontant in 2008. Only four genotypes, FVC11-015, FVC11-021, FVC11-022, and FVC11-031, were deemed remontant in 2007 and not 2008, of which all were "weak" except for FVC11-031, which did not survive
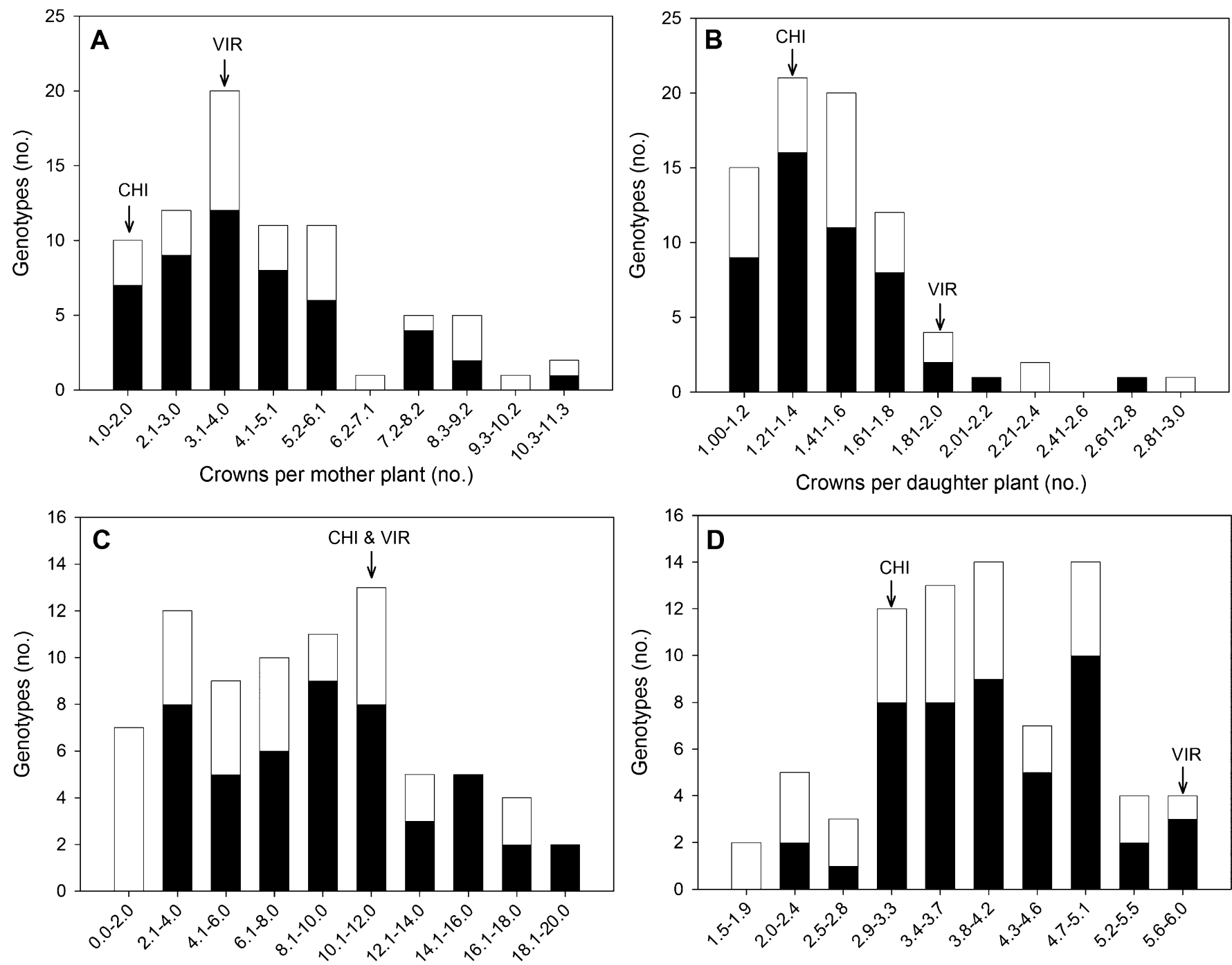

Daughter plants per mother plant (no.)

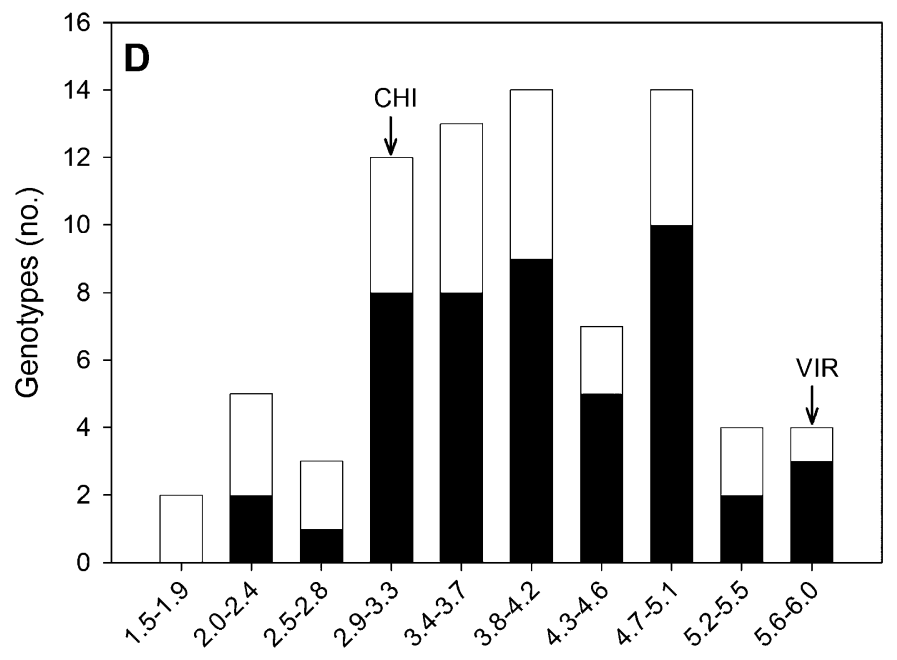

Plant vigor

Fig. 2. Number of FVC11 genotypes at Benton Harbor, MI, that had different numbers of crowns per mother plant (A), number of crowns per daughter plant (B), number of daughter plants per mother plant $(\mathbf{C})$, and plant vigor ratings $(\mathbf{D})$ in 2008. Black bars denote progeny that were non-remontant, whereas white bars denote progeny that were remontant. Arrows show the values of the Fragaria virginiana (VIR) and $F$. chiloensis $(\mathrm{CHI})$ parents. 

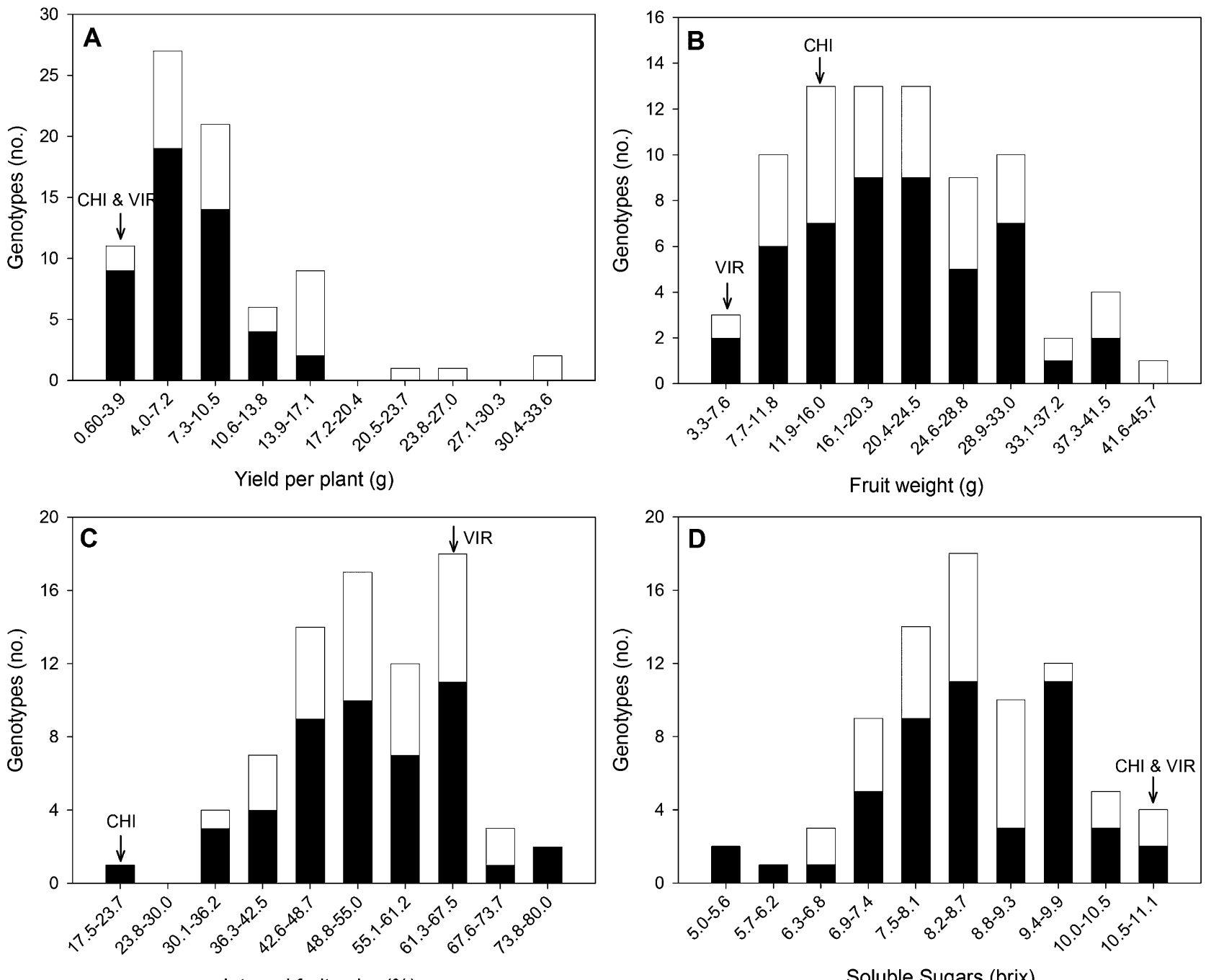

Internal fruit color (\%)

Soluble Sugars (brix)

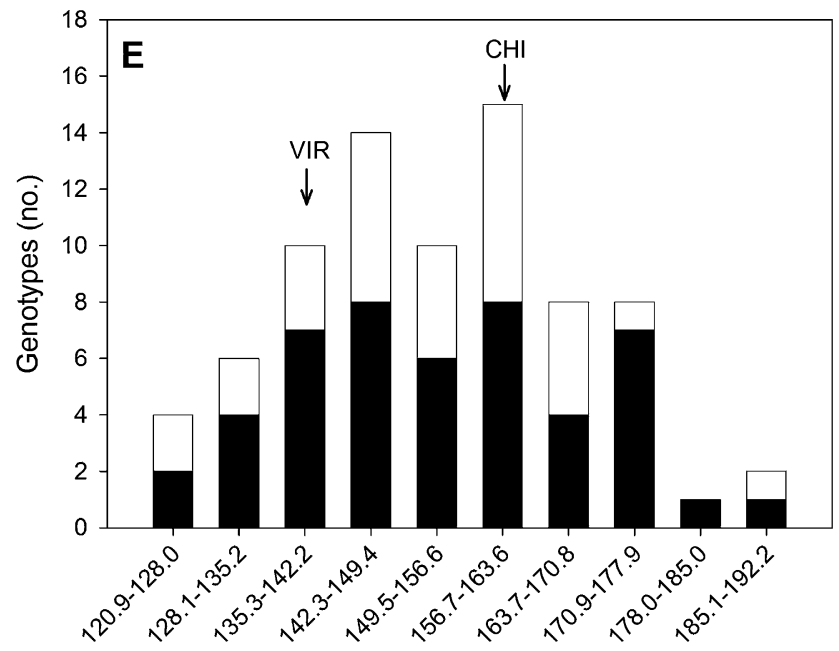

Fruit firmness $\left(\mathrm{g} \cdot \mathrm{mm}^{-2}\right)$

Fig. 3. Number of FVC 11 genotypes at Benton Harbor, MI, that had different yields per plant (A), mean fruit weights (B), percent internal fruit color (C) soluble sugars (D), and fruit firmness (E) in 2008. Black bars denote progeny that were non-remontant, whereas white bars denote progeny that were remontant. Arrows show the values of the Fragaria virginiana (VIR) and F. chiloensis (CHI) parents.

the winter. In 2008, nine genotypes were rated remontant that were non-remontant in 2007: FVC11-043, FVC11-048, FVC11-055, FVC11070, and FVC11-077, which were weakly remontant, and FVC11-014, FVC11-035,
FVC11-054, and FVC11-066, which were strongly remontant. The mean values of remontant and non-remontant genotypes were not significantly different $(P>0.05)$ for most traits, with the exception of yield per plant, daughter plants per mother, inflorescences per mother, and vigor (Table 1).

Many progeny displayed transgressive segregation with their trait values being higher than those of their parental genotypes. 


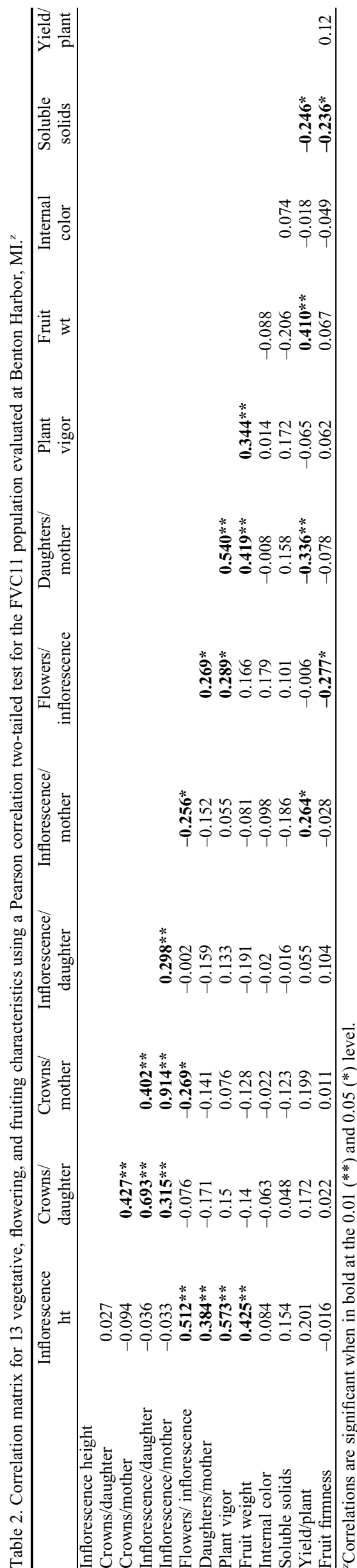

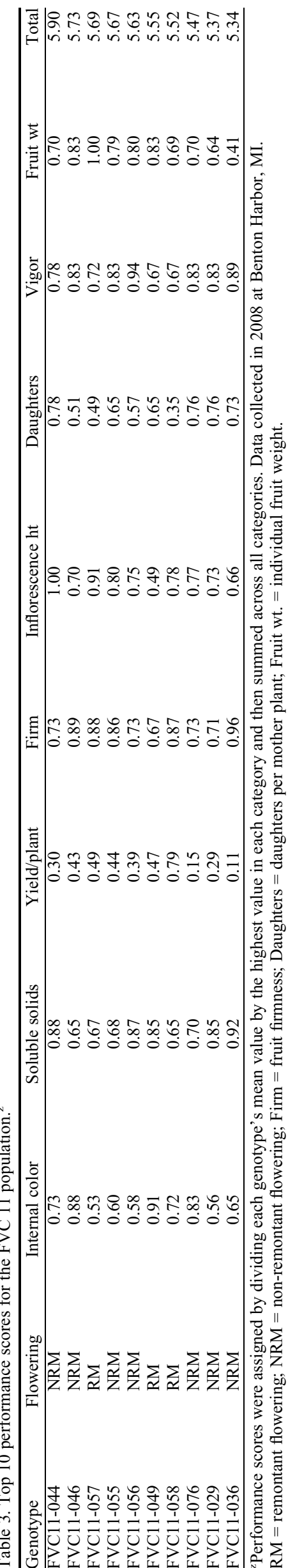

Only for soluble solids and plant vigor were no transgressive segregants observed (Fig. 13 ). Significant negative correlations were observed between fruit firmness and flowers per inflorescence, fruit firmness and soluble solids, yield per plant and soluble solids, yield per plant and daughter plants per mother, flower number per inflorescence and crown number per mother plant, and flower number per inflorescence and inflorescence number per mother plant (Table 2). All other significant correlations were positive. Only internal fruit color was not significantly correlated with any of the other traits studied. A significant negative correlation $(P=0.03)$ was found between the heaviest fruit weight of each genotype and soluble solids and between mean fruit weight and soluble solids at the $P=$ 0.07 level.

The total performance values for each genotype ranged from 3.38 to 5.90 (out of a possible 8) (Table 3). Values for the top 10 genotypes ranged from 5.34 to 5.90. The top 10 genotypes included three genotypes: FVC11-049, FVC11-057, and FVC11-058, that were remontant. The rest of the top 10 genotypes were all non-remontant.

\section{Discussion}

The reconstruction of $F$. Xananassa by crossing elite genotypes of $F$. chiloensis and $F$. virginiana appears to be an effective strategy for strawberry improvement. Although none of the examined FVC11 genotypes are of commercial quality, many have characteristics superior to their parents. In the relatively small FVC11 population, individuals were identified that have high levels for several horticulturally important traits and that could be used as parents to broaden the genetic base of the cultivated strawberry. Superior remontant and non-remontant individuals were identified.

Shaw (1988) warns that care must be taken to not only consider size when using wild germplasm to avoid narrowing the germplasm base for other important traits. Many of the FVC11 genotypes were superior for multiple traits. Where negative correlations were observed between characteristics such as between soluble solids and fruit weight and soluble solids and yield per plant, outliers could be found. For example, FVC11-049 had a 0.85 performance value for soluble solids and a 0.83 fruit weight value, whereas FVC11-059 had a 0.74 soluble solids value and a 0.95 yield per plant value. In fact, FVC11-044 had values of 0.70 or higher for seven of the eight traits examined.

The question remains as to whether intercrossing within the reconstructed populations will yield new cultivars. Although the fruit size in the best FVC11 genotypes is far superior to any wild germplasm, it is still smaller than commercial size. The most rapid breeding progress may be made by back-crossing the best FVC11 genotypes to cultivars. However, too many generations of back-crossing runs the risk of losing much of the genetic variation and novel epistatic interactions contained in the 
genotypes of FVC11. After six generations, a back-crossing approach leaves on average only $1.56 \%$ of the wild species in the selected germplasm (Dale et al., 1993). A large part of the genetic variance for fruit size is epistatic (Hancock et al., 2008), so maximizing allelic diversity could increase the occurrence of larger fruit when using wild germplasm.

With proper assessments of wild germplasm for most horticulturally important traits, many beneficial traits can be introgressed with minimal amounts of linkage drag. With the use of genetic markers, these traits could be more easily followed in a breeding program. Because of this, several available simple sequence repeat markers have been screened with a subset of this population to determine if they displayed polymorphisms and therefore could be used on futures studies with this population. The FVC11 population evaluated here would be a great tool to breeders wishing to introduce novel genetic diversity into their breeding programs. We are currently expanding this population to increase the chances of acquiring genotypes with even more positive combinations of traits.

\section{Literature Cited}

Barritt, B.H. and C.H. Shanks, Jr. 1980. Breeding strawberries for resistance to the aphids Chaetosiphon fragaefolii and C. thomasi. HortScience 5:287-288.

Bradford, E., J.F. Hancock, and R.M. Warner. 2010. Interactions of temperature and photoperiod determine repeat flowering in strawberry. J. Amer. Soc. Hort. Sci. 135:1-6.

Bringhurst, R.S., J.F. Hancock, and V. Voth. 1977. The beach strawberry, an important natural resource. Calif. Agr. 31:10.
Bringhurst, R.S. and V. Voth. 1978. Origin and evolutionary potentiality of the day-neutral trait in octoploid Fragaria. Genetics 90:510.

Bringhurst, R.S. and V. Voth. 1984. Breeding octoploid strawberries. Iowa St. J. Res. 58:371-381.

Cameron, J.S. and C.A. Hartley. 1990. Gas exchange characteristics of Fragaria chiloensis genotypes. HortScience 25:327-329.

Dale, A. and T.M. Sjulin. 1990. Few cytoplasms contribute to North American strawberry cultivars. HortScience 25:1341-1342.

Dale, A., H.A. Daubeny, M. Luffman, and J.A Sullivan. 1993. Development of Fragaria germplasm in Canada. Acta Hort. 348:75-80.

Daubeny, H.A. 1990. Strawberry breeding in Canada. HortScience 25:893-894.

Galletta, G.J., A.D. Draper, and J.L. Maas. 1989. Combining disease resistance, plant adaptation and fruit quality in breeding short day and dayneutral strawberries. Acta Hort. 285:43-51.

Hancock, J., A. Dale, and J. Luby. 1993. Should we reconstruct the strawberry? Acta Hort. 348:86-91.

Hancock, J.F. 1999. Strawberries. CABI Publishing, Wallingford, UK

Hancock, J.F., P.W. Callow, A. Dale, J.J. Luby, C.E. Finn, S.C. Hokanson, and K.E. Hummer. 2001a. From the Andes to the Rockies: Native strawberry collection and utilization. HortScience 36:221-225.

Hancock, J.F., C.E. Finn, S.C. Hokanson, J.J. Luby, B.L. Goulart, K. Demchak, P.W. Callow, S. Serçe, A.M.C. Schilder, and K.E. Hummer. 2001b. A multistate comparison of native octoploid strawberries from North and South America. J. Amer. Soc. Hort. Sci. 126:579-586.

Hancock, J.F., C.E. Finn, J.J. Luby, A. Dale, P.W Callow, and S. Serce. 2010. Reconstruction of the strawberry, Fragaria Xananassa, using genotypes of $F$. virginiana and $F$. chiloensis. HortScience 45:1006-1013.

Hancock, J.F., J.J. Luby, A. Dale, P.W. Callow, S. Serçe, and A. El-Shiek. 2002. Utilizing wild Fragaria virginiana in strawberry cultivar development: Inheritance of photoperiod sensitivity, fruit size, gender, female fertility and disease resistance. Euphytica 126:177-184.

Hancock, J.F., T.M. Sjulin, and G.A. Lobos. 2008. Strawberries, p. 393-437. In: Hancock, J.F. (ed.). Temperate fruit crop breeding. Springer Science+Business Media B.V., New York.

Luby, J.J., J.F. Hancock, and J.C. Cameron. 1991. Expansion of the strawberry germplasm base in North America, p. 66-75. In: Dale, A. and J. Luby (eds.). The Strawberry into the 21 st century. Timber Press, Portland, OR.

Luby, J.J. and M.M. Stahler. 1993. Collection and evaluation of Fragaria virginiana in North America. Acta Hort. 345:49-53.

Niemirowicz-Szczytt, K. 1989. Preliminary studies on inbreeding in strawberry Fragaria $\times$ ananassa Duch. Acta Hort. 265:97-104.

Scott, D.H. 1959. Size, firmness and time of ripening of fruit of seedlings of Fragaria virginiana Duch. crossed with cultivated strawberry varieties. Proc. Amer. Soc. Hort. Sci. 74: 388-393.

Scott, D.H., A.D. Draper, and L.W. Greeley. 1972. Interspecific hybridization in octoploid strawberries. HortScience 7:382-384.

Scott, D.H. and F.J. Lawrence. 1975. Strawberries, p. 71-97. In: Janick, J. and J.N. Moore (eds.). Advances in fruit breeding. Purdue Univ. Press, West Lafayette, IN.

Shaw, D.V. 1988. Genotypic variation and genotypic correlations for sugars and organic acids of strawberries. J. Amer. Soc. Hort. Sci. 113: 770-774.

Shaw, D.V. 1991. Recent advances in the genetics of strawberry, p. 76-83. In: Dale, A. and J. Luby (eds.). The Strawberry into the 21st century. Timber Press, Portland, OR.

Sjulin, T.M. and A. Dale. 1987. Genetic diversity of North American strawberry cultivars. J. Amer. Soc. Hort. Sci. 112:375-385. 